AUTHOR's REPLY, - Both the study that is commented on' and the update of the Steno studies 1 and $2^{2}$ suggest that in normotensive patients with microalbuminuria those with the highest baseline urinary albumin excretion (100-300 $\mathrm{mg} / 24 \mathrm{~h}$ ) benefit most from the treatment. In addition, the spontaneous progression of urinary albumin excretion in patients with initial values between 30 and $100 \mathrm{mg} / 24 \mathrm{~h}$ was slow, at only $3 \%$ a year. The progression of microalbuminuria is also determined by the level of metabolic control and arterial blood pressure. Therefore, the arterial blood pressure, haemoglobin $A_{\mathrm{lc}}$ concentration, and urinary albumin excretion must be taken into account when the possible treatment for an individual patient with persistent microalbuminuria is evaluated.

We are still, however, unable to discriminate exactly between patients with persistent microalbuminuria who have a high as against a low risk of progression to nephropathy. Before this can be done longitudinal studies of the spontaneous course of the renal disease in insulin dependent diabetic patients with persistent microalbuminuria are needed, analysing the relative importance for progression to nephropathy of metabolic control, systemic blood pressure, baseline urinary albumin excretion, glomerular hyperfiltration, protein intake, serum lipid concentrations, etc.

In reply to Neil A Solomon, we have shown previously shown that a short term reduction in systemic blood pressure of $15 \mathrm{~mm} \mathrm{Hg}$ leads to a significant reduction in urinary albumin excretion in normotensive patients with microalbuminuria. ${ }^{3}$ The goal of the present study ${ }^{1}$ was to prevent the expected rise in arterial blood pressure and, if possible, to reduce the diastolic blood pressure by $5 \mathrm{~mm} \mathrm{Hg}$ in the treatment group. The mean diastolic blood pressure in the two groups was evaluated at six, 12, and 24 months. If the desired effect was not achieved the dose of captopril was subsequently doubled for every patient in the treatment group. At a given time all treated patients received the same dose of captopril and during the last 18 months also bendrofluazide. The change in the blood pressure and urinary albumin excretion in relation to the dose of captopril can be evaluated from figure 1. Neither at the start of the treatment nor when the dose was increased could any significant acute change in systemic blood pressure and urinary albumin excretion be detected.

In the control group the increase in urinary albumin excretion was not dependent on the baseline systemic blood pressure. When all values measured during the four year observation period were included in the calculations, however, a significant correlation between the changes in systemic blood pressure and in urinary albumin excretion was seen in the control group. No such correlation between the changes in systemic blood pressure and in urinary albumin excretion could be shown in the captopril group. The increase in systemic blood pressure may be secondary to the increase in urinary albumin excretion in patients with microalbuminuria, as previously suggested. ${ }^{+}$ In seven of the 23 control patients and in 10 of the 21 treated patients a fall in diastolic blood pressure of at least $5 \mathrm{~mm} \mathrm{Hg}$ was seen (not significant). Consequently, I do not find it reasonable to divide the patients into those who did and those who did not respond to treatment based on the blood pressure response as suggested.

Klavs Würgler Hansen has focused on the individual systemic blood pressure measured at baseline and at four year follow up (table II). ${ }^{1}$ Unfortunately, he has missed table II, where we gave the annual change in blood pressure in the two groups. The precision of the figures was improved by including in the calculations all values measured during the four year observation period. The mean ( $95 \%$ confidence interval) change in blood pressure was $-0.4(-1$ to 1$) /-1(-1$ to 0$) \mathrm{mm} \mathrm{Hg}$ a year in the captopril treated group and $-0.3(-1$ to 1$) /$
-0.7 ( -2 to 0$) \mathrm{mm} \mathrm{Hg}$ a year in the control group. These figures clearly showed that there was no significant difference in the annual change in blood pressure between the two groups.

In the present study it seems reasonable to conclude that the effect of captopril on the progression of the renal disease seemed to be independent of changes in systemic blood pressure. The gradual improvement in the urinary albumin excretion rate during treatment with captopril leads to the suggestion that a gradual improved selectivity of the glomerular barrier was the most important pathophysiological factor. I suggest that the effective dose of captopril is in the range $50-100 \mathrm{mg} / 24 \mathrm{~h}$.

Steno Memorial and Hvidore Hospital,

ELISABETH R MATHIESEN

2820 Gentofte,

Denmark

1 Mathiesen ER, Hommel E, Giese J, Parving H-H. Efficacy of captopril in postponing nephropathy in normotensive insulin dependent diabetic patients with microalbuminuria. $B M \mathcal{F}$ 1991;303:81-7. (13 July.)

2 Feldt-Rasmussen B, Mathiesen ER, Deckert T. Effect of two years of strict metabolic control on progression of incipient years of strict metabolic control on progression of incipient nephropath.

3 Hommel E, Mathiesen ER, Edsberg B, Bahnsen M, Parving Hommel E, Mathiesen ER, Edsberg B, Bahnsen M, Parving
H-H. Acute reduction of arterial blood pressure reduces $\mathrm{H}-\mathrm{H}$. Acute reduction of arterial blood pressure reduces
urinary albumin excretion in type 1 (insulin-dependent) urinary albumin excretion in type 1 (insulin-dependent)
diabetic patients with incipient nephropathy. Diabetologia diabetic patien

Mathiesen ER, Oxenboll B, Johansen K, Svendsen PA, Deckert $\mathrm{T}$. Incipient nephropathy in type 1 (insulin-dependent) diabetes. Diabetologia 1984;26:406-10.

\section{Aprotinin and cardiac surgery}

SIR, - We thank D W Bethune ${ }^{1}$ and Lindsay C H John and colleagues ${ }^{2}$ for their comments on our editorial on aprotinin and cardiac surgery. ${ }^{3} \mathrm{Dr}$ Bethune ${ }^{1}$ suggested that there was evidence from Wang $e t a l^{4}$ that the prolongation of the activated clotting time seen when aprotinin is used during cardiopulmonary bypass surgery was an artefact caused by an interaction between the celite activator, heparin and aprotinin. We have performed similar experiments studying the effects of aprotinin on the activated partial thromboplastin time and the activated clotting time. ${ }^{5}$ Aprotinin produced a dose dependent prolongation of both times with and without heparin; this occurred whether the activator was kaolin, celite, or micronised silica. Prolongation of clotting times which measure intrinsic pathway activation such as the activated partial thromboplastin time and the activated clotting time are to be expected with aprotinin, for as aprotinin inhibits kallikrein, an amplifier of intrinsic pathway activation, intrinsic coagulation activation will be limited and so prolong clotting times.

The comment from Dr John et $a l^{2}$ that aprotinin may reverse an in vitro platelet inhibition related to heparin is an interesting hypothesis, and we look forward to seeing the original data. This does not, however, explain the efficacy of aprotinin in reducing perioperative bleeding in liver transplantation and vascular surgery when cardiopulmonary bypass and systemic heparinisation are not used and thus platelet damage is not induced. This led us to suggest that aprotinin's major mode of action is through its potent antifibrinolytic action rather than any major effect on platelets. The comments elicited by our editorial highlight the need for more research into the mechanisms of action of aprotinin.

BEVERLEY J HUNT MAGDI YACOUB

Harefield Hospital,

Harefield,

Middlesex UB9 6JH

I Bethune DW. Aprotinin and cardiac surgery. BMf 1991;303:991 19 October.)

John LCH, Rees GM, Kovac IB. Aprotinin and cardiac surgery. BMF 1991;303:991-2.
3 Hunt BJ, Yacoub M. Aprotinin and cardiac surgery. BMJ 1991;303:660-1. (21 September.)

4 Wang J-S, Hung W-T, Karp R, Lun C-Y. Increase in ACT of heparinised blood in patients on aprotinin is caused by the celite activator. In: Abstracts presented at the 13th annual meetin of the Society of Cardiovascular Anaesthesiologists, San Antonio, Texas 5-8 May 1991. Richmond, Virginia: Society of Cardiovascular Anaesthesiologists, 1991 .

5 Hunt BJ, Segal H, Yacoub M. Monitoring heparin by the activated clotting time when aprotinin is used during cardiopulmonary bypass. Thromb Haemost 1991;65:1025.

\section{Glasgow coma scale and gag reflex}

SIR, - C Moulton and colleagues have shown that the gag reflex may be impaired in apparently conscious patients requiring neurological observation in an accident and emergency department. They recommend that the gag reflex should be assessed independently of the conscious level and used as an indicator of an "at risk" airway. Horner et al, however, showed in a series of 47 patients with stroke that the presence or absence of the gag reflex did not independently predict aspiration. ${ }^{2}$

The authors also mention that other reflexes are protective of the airway. It seems that the cough and swallow reflexes, though difficult to quantify, are more important in protecting the airway. In a series of 53 patients with closed head trauma a delayed or absent swallowing reflex, as shown by videofluoroscopy, was the most common cause of aspiration. ${ }^{3}$ Another study of people with aspiration pneumonia showed an association with an impaired cough reflex. ${ }^{4}$

I therefore warn against relying unduly on a normal gag reflex indicating a safe airway. If there is doubt about whether patients are at risk of aspiration, ensuring that they receive "nil by mouth" until they improve or seeking a speech therapy assessment and then performing videofluoroscopy would be the safest course of action.

Department of Medicine for the Elderly,

A J STANNERS

St James's University Hospital,

Leeds LS97TF

1 Moulton C, Pennycock A, Makover R. Relation between Glasgow coma scale and the gag reflex. BMF 1991;303:1240-1. (16 November.)

2 Horner J, Massey EW, Riski JE, Lathrop DL, Chase KN. Aspiration following stroke: clinical correlates and outcome. Neurology 1988;38:1359-62.

3 Lazarus C, Logemann JA. Swallowing disorders in closed head trauma patients. Arch Phys Med Rehabil 1987;68:79-84.

4 Sekizawa K, Ujiie Y, Itabashi S, Sasaki.H, Takishima T. Lack of cough reflex in aspiration pneumonia. Lancet 1990;335:1228-9.

\section{Rugby injuries}

SIR,-Having some experience of rugby injuries, I entirely agree with W M Garroway and colleagues that problems exist "with both the numerator and the denominator"' as the total number of rugby players in the United Kingdom is not known, only the number of clubs; similarly, the number of games in which each player takes part each week is not known. This problem with the numerator and the denominator makes injury rates a matter of speculation.

When I looked at catastrophic injuries to 67 rugby players in $1984^{2}$ and a further 19 players in $1988^{3}$ it took a great deal of time to obtain accurate information about how they had been sustained. I wrote:

It is salutary to realise that, although it is such a catastrophic injury for which compensation would be payable (all members of affiliated clubs have to be covered by insurance), neither the Welsh Rugby Union nor the Rugby Football Union had information on 2 such injuries from their insurance company, or information on a further 7 which were on record. This situation was due to clubs and schools failing to inform their respective national unions, which makes any calculation based on the official figures available to the 